05

\title{
Влияние равноканального углового прессования и гидростатического давления на упругие и микропластические свойства сплава $\mathrm{Cu}-0.2$ wt. \% Zr
}

\author{
(C) Б.К. Кардашев, ${ }^{1}$ В.И. Бетехтин, ${ }^{1,2}$ М.В. Нарыкова, ${ }^{1,}{ }^{\top}$ А.Г. Кадомцев, ${ }^{1}$ О.В. Амосова ${ }^{1}$ \\ ${ }^{1}$ Физико-технический институт им. А.Ф. Иофрее РАН, \\ 194021 Санкт-Петербург, Россия \\ 2 Тольяттинский государственный университет, \\ 445020 Тольятти, Россия \\ ฯ e-mail: Maria.Narykova@mail.ioffe.ru
}

Поступило в Редакцию 17 сентября 2018 г.

В окончательной редакции 22 марта 2019 г.

Принято к публикации 15 апреля 2019 г.

\begin{abstract}
Изучено и проанализировано влияние интенсивной пластической деформации и последующего воздействия высокого гидростатического давления на упругие и микропластические свойства сплава $\mathrm{Cu}-0.2 \mathrm{wt} \% \mathrm{Zr}$. Проведена оценка влияния на эти свойства нанопористости, которая образуется в процессе равноканального углового прессования и залечивается при наложении гидростатического давления.
\end{abstract}

Ключевые слова: РКУП, $\mathrm{Cu}-\mathrm{Zr}$, модуль Юнга, декремент, условный предел микротекучести, упруго-пластические свойства.

DOI: 10.21883/JTF.2019.10.48172.341-18

\section{Введение}

Известно, что микро- и субмикрокристаллические (МСM) металлы и сплавы, полученные при интенсивной пластической деформации (ИПД) методом равноканального углового прессования (РКУП), имеют высокие значения микротвердости, предела прочности и текучести; в настоящее время выявлены основные структурные особенности, обусловливающие эти механические свойства [1-5]. Упруго-пластические характеристики МСМ металлических материалов и природа структурных факторов их определяющих изучены существенно меньше [5-7]. Между тем уровень упругих и пластических свойств этих материалов важен для многих областей техники и биомедицины $[3,8]$.

В настоящей работе исследовались акустические (упругие и микропластические) свойства сплава $\mathrm{Cu}-\mathrm{Zr}$. Интерес к этому материалу обусловлен тем, что медь и ее сплавы имеют высокую электропроводность и находят широкое практическое применение. Отметим, что некоторые особенности электропроводности и ее связи с упругими характеристиками МСМ металлов рассмотрены авторами в [9].

Для изучения природы структурных факторов, влияющих на упруго-пластические свойства МСМ сплава $\mathrm{Cu}-\mathrm{Zr}$, эти свойства определялись до и после воздействия высокого гидростатического давления, которое ведет к залечиванию [10] образовавшихся при ИПД нанопор. При анализе особенностей структуры, влияющих на свойства сплава $\mathrm{Cu}-\mathrm{Zr}$, в дальнейшем будут использованы результаты структурных исследований, полученные ранее в [11].

\section{Материал и экспериментальные методы}

Исследуемый сплав $\mathrm{Cu}-0.2$ wt\% $\mathrm{Zr}$ подвергался гомогенизирующему отжигу при $1025 \mathrm{~K}$ в течение $24 \mathrm{~h}$, затем холодной прокатке и вторичному отжигу при $1233 \mathrm{~K}$ в течение $1 \mathrm{~h}$. После такой обработки размер зерен в сплаве достигал $350 \mu \mathrm{m}$. Затем сплав подвергался разному (от 1 до 12) числу проходов при РКУП (с поворотом на $90^{\circ}$ после каждого прохода) при комнатной температуре. Из полученных после этого заготовок ${ }^{1}$ для акустических измерений приготовлялись образцы в форме стержней прямоугольного поперечного сечения $\sim 2 \times 2 \mathrm{~mm}^{2}$ длиной $\sim 18 \mathrm{~mm}$.

В настоящей работе, как и в $[6,7,12]$, для изучения упругих и микропластических свойств использовался резонансный метод составного пьезоэлектрического вибратора. Длина образца $l \approx 18 \mathrm{~mm}$ обеспечивала резонансную частоту продольных колебаний образца $f$ вблизи $100 \mathrm{kHz}$. Модуль Юнга определялся по формуле

$$
E=4 \rho l^{2} f^{2},
$$

где $\rho$ - плотность образца.

Метод составного вибратора [12] позволяет изучать поведение модуля Юнга $E$ и логарифмического декремента $\delta$ (внутреннего трения) в широком диапазоне амплитуд колебательной деформации $\varepsilon$, когда при достаточно больших $\varepsilon$ в материале образца возникает нелинейное, амплитудно-зависимое поглощение ультразву-

${ }^{1}$ Авторы выражают искреннюю благодарность профессору V. Sklenicka и его коллегам (ИФМ, Брно, Чешская республика) за предоставление заготовок сплава $\mathrm{Cu}-\mathrm{Zr}$ после его термообработки и РКУП. 
ка $\delta_{h}=\delta-\delta_{i}$ и амплитудно-зависимый дефект модуля Юнга

$$
(\Delta E / E)_{h}=\left(E-E_{i}\right) / E_{i} .
$$

Здесь $E_{i}$ и $\delta_{i}$ - значения модуля Юнга и декремента, измеряемые при малых амплитудах, где модуль $E$ и декремент $\delta$ еще не зависят от $\varepsilon$.

В настоящей работе, как и в [6,7], по результатам измерений амплитудных зависимостей $E(\varepsilon)$ строились диаграммы „напряжение-неупругая деформация“. Для этого по оси ординат откладывались значения амплитуд колебательных напряжений $\sigma=E \varepsilon$, а по оси абсцисс нелинейная неупругая деформация

$$
\varepsilon_{d}=\varepsilon(\Delta E / E)_{h} .
$$

Эти данные позволяют прослеживать за изменением микропластических свойств материала в зависимости от предыстории образца на уровне неупругих деформаций от $10^{-9}$ до $10^{-6}$ и оценивать величину условного предела микротекучести $\sigma_{s}$.

Плотность образцов после разного числа проходов РКУП и после воздействия высокого (1.5 GPa) давления определялась прецизионным методом гидростатического взвешивания, относительная погрешность не превышала $2 \cdot 10^{-4}$. Измерение плотности и воздействие гидростатического давления проводились при комнатной температуре. Отметим, что, согласно электронно-микроскопическим исследованиям, проведенным в [10], размер зерен в результате РКУП уменьшался от 350 до (после 12 проходов) $0.35 \mu \mathrm{m}$; сплав содержал преципитаты $\mathrm{Cu}_{9} \mathrm{Zr}_{2}$ размером от 1 до $10 \mathrm{~nm}$.

\section{Экспериментальные данные и их обсуждение}

Основные экспериментальные данные, полученные в настоящей работе, представлены на рис. 1, 2 и в таблице. В качестве примера на рис. 1, $a$ приводятся амплитудные зависимости модуля Юнга $E$ и декремента $\delta$, полученные на образцах $\mathrm{Cu}-0.2 \mathrm{wt} \% \mathrm{Zr}$, как в исходном состоянии, так и после воздействия на образец гидростатического давления. Рис. $1, b$ представляет аналогичные данные для образцов $\mathrm{Cu}-0.2 \mathrm{wt} \% \mathrm{Zr}$, подвергнутых четырем проходам РКУП. При сопоставлении данных рис. $1, a$ и $b$ видно, что если в исходном состоянии (без РКУП) после приложения гидростатического давления модуль $E$ уменьшается, а декремент растет, то после РКУП давление заметно увеличивает модуль, а затухание ультразвука меняется мало. Подобные данные получены и на других образцах $\mathrm{Cu}-0.2 \mathrm{wt} \% \mathrm{Zr}$ после 1 , 8 и 12 проходов РКУП.

На рис. 2, a показаны диаграммы „напряжение-неупругая деформация“" для образцов сплава $\mathrm{Cu}-0.2 \mathrm{wt} \% \mathrm{Zr}$ в исходном состоянии и после 4, 8 и 12 проходов РКУП, полученные по данным акустических измерений.
Плотность $\rho$, модуль Юнга $E$, амплитудно-независимый декремент $\delta_{i}$ и условный предел микротекучести $\sigma_{s}$ при неупругой деформации $\varepsilon_{d}=2.0 \cdot 10^{-8}$ при 0, 1, 4, 12 проходах РКУП до и после (в скобках) приложения гидростатического давления

\begin{tabular}{c|c|c|c|c}
\hline Число проходов РКУП & $E, \mathrm{GPa}$ & $\delta_{i}, 10^{-3}$ & $\sigma_{s}, \mathrm{MPa}$ & $\rho, \mathrm{g} / \mathrm{cm}^{3}$ \\
\hline \multirow{2}{*}{0} & 119.93 & 34 & 7.9 & 8.908 \\
& $(119.05)$ & $(128)$ & $(4.2)$ & $(8.909)$ \\
1 & 134 & 33 & 8.1 & 8.886 \\
& $(136)$ & $(45)$ & $(11)$ & $(8.900)$ \\
4 & 132.9 & 36 & 10.4 & 8.884 \\
\multirow{2}{*}{12} & $(137.3)$ & $(40)$ & $(14.2)$ & $(8.896)$ \\
& 135.6 & 33 & 18.5 & 8.865 \\
& $(133.05)$ & $(17)$ & $(21.7)$ & $(8.909)$
\end{tabular}

На рис. 2, $b$ данные относятся к образцам, подвергнутым РКУП, а затем - воздействию гидростатического давления. Из рисунков видно, что увеличение числа проходов РКУП последовательно упрочняет материал: при большей предварительной пластической деформации сплава для одной и той же деформации $\varepsilon_{d}$ необходимо более высокое напряжение $\sigma$.

Значения модуля Юнга $E$, декремента $\delta_{i}$ и величин условного предела микротекучести $\sigma_{s}$ образцов сплава $\mathrm{Cu}-0.2 \mathrm{wt} \% \mathrm{Zr}$ для наглядности обсуждения сведены в таблицу.

При рассмотрении данных таблицы следует обратить внимание на следующее. Модуль Юнга после одного прохода РКУП увеличивается от $\sim 119$ до $\sim 130 \mathrm{GPa} \mathrm{и}$ в дальнейшем (при увеличении числа проходов) остается практически на постоянном уровне с небольшими колебаниями в ту или иную сторону. Такое поведение действующего (измеряемого) модуля упругости можно объяснить совместным влиянием дислокационной деформации, которая может менять модуль как в сторону увеличения, так и в сторону уменьшения за счет увеличения плотности дислокаций и уменьшения характерной длины дислокационных сегментов [12,13], а также образованием при РКУП высоких внутренних напряжений $[14,15]$. На модуль $E$ может влиять также изменение при РКУП плотности (см. таблицу), которая, как показано в $[10,16]$, во многом обусловлена образованием нанопор размером $\sim 10-30 \mathrm{~nm}$. Однако с учетом всех структурных факторов резкий рост $E$ после первых проходов РКУП обусловлен в основном появлением высоких внутренних напряжений. Аналогичный вывод был сделан ранее для $\mathrm{Al}$ и $\mathrm{Ti}[6,7,17]$.

Таким же образом объясняется поведение декремента $\delta_{i}$, с той лишь разницей, что внутренние напряжения не должны оказывать влияния на этот параметр. Здесь интересно отметить практическое постоянство декремента независимо от числа проходов РКУП для образцов, которые в дальнейшем не подвергались воздействию гидростатического давления. Что касается данных по $\delta_{i}$ для образцов после приложения гидростатического 

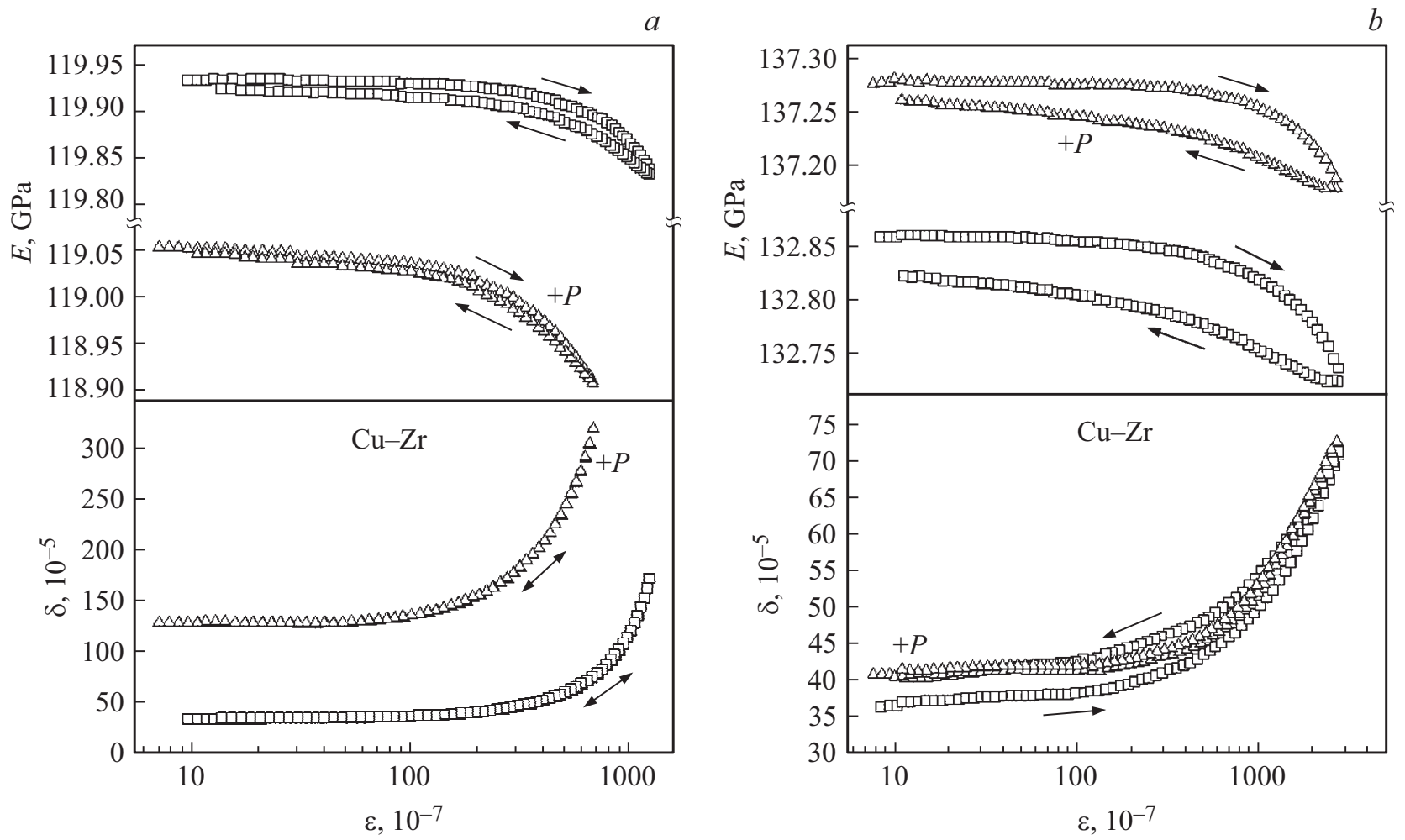

Рис. 1. Амплитудные зависимости модуля Юнга $E$ и декремента $\delta$, измеренные на образцах сплава Сu- $\mathrm{Zr}$ в исходном состоянии $(a)$ и после 4-х проходов РКУП $(b)$ до и после приложения гидростатического давления $(+P)$; стрелки указывают направление изменения амплитуды; измерения проводились при комнатной температуре после длительной выдержки при $\sim 20^{\circ} \mathrm{C}$.
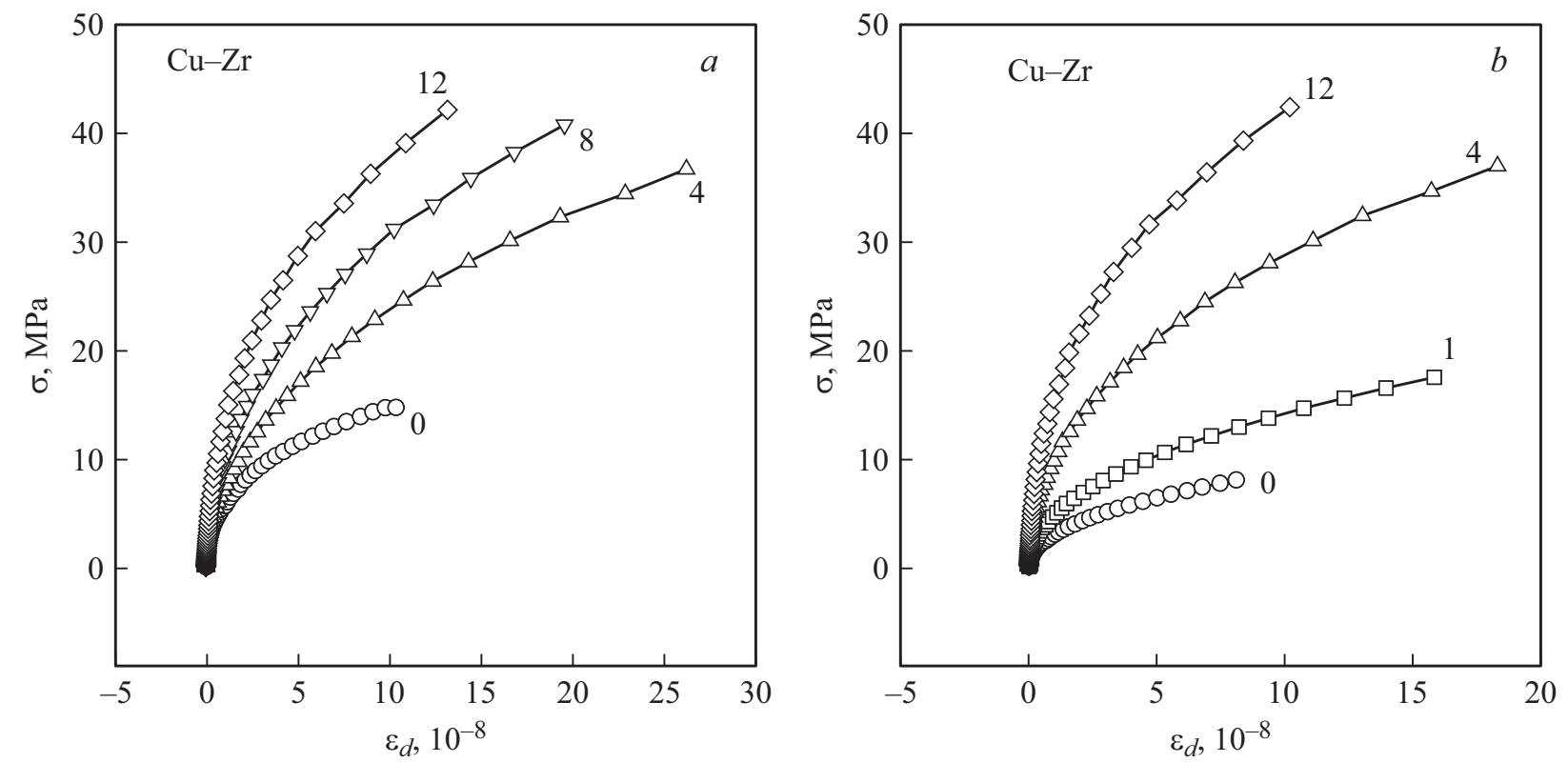

Рис. 2. Диаграммы „напряжение-неупругая деформация“ для образцов сплава $\mathrm{Cu}-\mathrm{Zr}$ в исходном состоянии (0) и после различного числа проходов РКУП до $(a)$ и после $(b)$ приложения гидростатического давления; измерения выполнены при комнатной температуре.

давления, то здесь имеет место монотонное уменьшение декремента с увеличением числа проходов РКУП. Для образца, который не подвергался РКУП, обращает на себя внимание значительный рост декремента после воздействия гидростатического давления (с $34 \cdot 10^{-5}$ до $\left.128 \cdot 10^{-5}\right)$. Очевидно, что здесь под давлением возникают свежие дислокации (скорее всего из-за наличия преципитатов), что, как обычно для пластичных кри- 
сталлических материалов [12,13], уменьшает модуль и увеличивает декремент.

Для условного предела микротекучести характерным является рост значений $\sigma_{s}$ с увеличением числа проходов РКУП. Однако здесь так же, как и для модуля и декремента, имеет место обычное для пластичных кристаллических материалов уменьшение $\sigma_{s}$ после небольшой пластической деформации, что видно при сравнении данных для образцов, не подвергавшихся воздействию РКУП ( $\sigma_{s}$ уменьшается с 7.9 до $\left.4.2 \mathrm{MPa}\right)$. Для образцов с 4, 8 и 12 проходами РКУП наблюдается увеличение $\sigma_{s}$ как до, так и после приложения гидростатического давления. Это может быть связано с изменениями дислокационной структуры и с уменьшением нанопористости; после ее залечивания под давлением эффект роста $\sigma_{s}$ повышается.

\section{Заключение}

В работе изучено поведение модуля Юнга, логарифмического декремента, а также микропластических характеристик сплава $\mathrm{Cu}-0.2 \mathrm{wt} \% \mathrm{Zr}$ после интенсивной пластической деформации методом РКУП и последующего воздействия на образцы высокого гидростатического давления. Показано, что РКУП увеличивает модуль Юнга и уровень напряжений микропластического течения, а величина декремента остается практически постоянной. Существенное увеличение модуля упругости после РКУП обусловлено появлением высоких внутренних напряжений. Рост предела микротекучести с увеличением числа проходов РКУП является характерным, что связано с изменением дислокационной структуры. Проведена оценка влияния пористости, которая образуется в процессе РКУП и залечивается при наложении гидростатического давления. Немонотонное изменение модуля упругости после обработки давлением можно объяснить совместным влиянием дислокационной деформации, изменением уровня внутренних напряжений, а также эволюцией нанопористости.

\section{Финансирование работы}

Работа выполнена при финансовой поддержки российского фонда фундаментальных исследований (проект № 18-08-00360).

\section{Конфликт интересов}

Авторы заявляют, что у них нет конфликта интересов.

\section{Список литературы}

[1] Сегал М., Резников А.Е., Копылов В.И. // Изв. АН СССР. Металлы. 1981. Т 1. С. 113-122.

[2] Gleiter H. // Progr. Mater. Sci. 1989. Vol. 33. P. 233-251.

[3] Zeheibauer M.J., Zhu Y.T. Bulk nanostructure materials. Wiley-VCH, Weiheim, 2009. 736 p.
[4] Валиев Р.З., Александров Г.В. Наноструктурные металлы, полученные интенсивной пластической деформацией. М.: Логос, 2000. 292 c.

[5] Андреевский Р.А., Глезер А.М. // УФН. 2009. Т. 179. Вып. 4. C. 337-358. [Andrievski R.A., Glezer A.M. // Physics-Uspekhi. 2009. Vol. 52. N 4. P. 315-334.]

[6] Кардашев Б.К., Бетехтин В.И., Нарыкова М.В. // ЖТФ. 2015. Т. 85. Вып. 12. С. 94-106. [Kardashev B.K., Betekhtin V.I., Narykova M.V. // Tech. Phys. 2015. Vol. 60. N 12. P. 1829-1841.] DOI: $10.1134 / \mathrm{S} 1063784215120063$

[7] Кардашев Б.К., Бетехтин В.И., Кадомщев А.Г., Нарыкова М.В., Колобов Ю.Р. // ЖТФ. 2017. Т. 87. Вып. 9. С. 1362 1366. [Kardashev B.K., Betekhtin V.I., Kadomtsev A.G., Narykova M.V. Kolobov Y.R. // Tech. Phys. 2017. Vol. 62. N 9. P. 1372-1376.] DOI: $10.1134 / \mathrm{S} 1063784217090110$

[8] Kolobov Y.R. // Nanotech. Russia. 2009. Vol. 11-12. P. $758-775$.

[9] Кардамев Б.К., Сапожников К.В., Бетехтин В.И., Кадомиев А.Г., Нарыкова М.В. // ФТТ. 2017. Т. 59. Вып. 12. C. 2358-2362. [Kardashev B.K., Sapozhnikov K.V., Betekhtin V.I., Kadomtsev A.G., Narykova M.V. // Phys. Solid State. 2017. Vol. 59. N 12. P. 2381-2386.] DOI: $10.1134 / \mathrm{S} 1063783417120204$

[10] Бетехтин В.И., Кадомиев А.Г., Sklenicka V., Saxl I. // ФТT. 2007. Т. 49. Вып. 10. С. 1787-1790. [Betekhtin V.I., Kadomtsev A.G., Sklenicka V., Saxl I. // Phys. Solid State. 2007. Vol. 49. N 10. P. 1874-1877.] DOI: $10.1134 /$ S1063783407100101

[11] Dvorak J., Sklenicka V., Betekhtin V.I., Kadomtsev A.G., Kral P., Svoboda M. // Mater. Sci. Eng. A. 2013. Vol. 584. P. 103-113. DOI: 10.1016/j.msea.2013.07.018

[12] Никаноров С.П., Кардашев Б.К. Упругость и дислокационная неупругость кристаллов. М.: Наука, 1985. 254 с.

[13] Gremaud G. // Mat. Sci. Forum. 2001. Vol. 178. P. 366-368.

[14] Chernov V.M., Kardashev B.K., Krjukova L.M., Mamaev L.I., Plaksin O.A., Rusanov A.E., Solonin M.I., Stepanov V.A., Votinov S.N., Zavialski L.P. // J. Nucl. Mater. 1998. Vol. 257. N 3. P. 263-269.

[15] Кардашев Б.К., Плаксин О.А., Степанов В.А., Чернов В.М. // ФТТ. 2004. Т. 46. Вып. 8. С. 1409-1415. [Kardashev B.K., Plaksin O.A.,Stepanov V.A., Chernov V.M. // Phys. Solid State. 2004. Vol. 46. N 8. P. 1449-1455.] DOI: $10.1134 / 1.1788777$

[16] Бетехтин В.И., Sklenicka V., Saxl I., Кардашев Б.К., Кадомцев А.Г., Нарыкова М.В. // ФТТ. 2010. Т. 52. Вып. 8. C. 1517-1523. [Betekhtin V.I., Sklenicka V., Saxl I., Kardashev B.K., Kadomtsev A.G., Narykova M.V. // Phys. Solid State. 2010. Vol. 52. N 8. P. 1629-1636.]

DOI: $10.1134 / \mathrm{S} 1063783410080111$

[17] Бетехтин В.И., Кадомиев А.Г., Кардамев Б.К. // ФТТ. 2006. Т. 48. Вып. 8. С. 1421-1427. [Betekhtin V.I., Kadomtsev A.G., Kardashev B.K. // Phys. Solid State. 2006. Vol. 48. N 8. P. $1506-1512$.] DOI: $10.1134 / \mathrm{S} 1063783406080142$ 